\title{
A NOTE ON CURRENCY
}

Until the 1960s, the Gold Coast/Ghana used the British pounds, shillings and pence ( $£$ s d) currency system, in which $£ 1$ equalled 20 shillings, and a shilling equalled 12 pence. The first attempt at decimalisation in the mid-1960s introduced the Cedi, equivalent to $8 \mathrm{~s} 4 \mathrm{~d}$ (i.e. 100 pence) of the old currency. This proved to be confusing to all, and, by the time of fieldwork, the New Cedi, equivalent to the old 10s, had replaced it. This was further divided into 100 pesewas. In 1969, thanks to devaluation, the New Cedi's official value was, rather conveniently, almost exactly one US dollar, though one could get up to 35 per cent more on the black market, depending on which Asian trader one dealt with. The word 'New' was gradually dropped. After so many subsequent years of hyperinflation, it is now sometimes difficult to recall that the Cedi has seen better days, but at the time of fieldwork it was still a substantial sum of money, more, in fact, than the daily minimum wage of 75 pesewas. 